\title{
Anti-Proliferative Effect of Specific Anti-EGFR Single Chain Antibody on Triple Negative Breast Cancer Cells
}

\author{
Forough Abdollahzadeh ${ }^{1}$, Foroogh Nejatollahi*1,2
}

\begin{abstract}
Background: Targeted therapy is an important treatment strategy that is widely used for cancer therapy. Epidermal growth factor receptor (EGFR) is overexpressed in a significant percentage of Triple-negative breast cancer (TNBC) patients. Although Cetuximab, which targets EGFR, has shown some inhibitory effects on TNBC cells, Cetuximab resistance cases due to ligand-independent activating mutations in the EGFR gene limit its application. Due to various benefits of single chain antibodies (scFvs), the use of these antibodies in cancer targeted therapy is increasing. In this study, a specific anti-EGFR antibody was isolated and evaluated.

Methods: Panning procedure was used against an immunodominant epitope of EGFR in its dimerization arm using a diverse phage library. Polymerase Chain Reaction (PCR) and fingerprinting were applied to identify the specific clones. The MTT tetrazolium assay was performed to evaluate the inhibitory effects of selected antiEGFR scFv phage antibody on MDA-MB-468, a TNBC cell line.

Results: After four round of panning, one dominant pattern was observed in DNA fingerprinting with frequency of $85 \%$. The growth of MDA-MB-468 cells was decreased dose-dependently after treatment with anti-EGFR scFv phage antibody. No significant inhibitory effect of $\mathrm{M} 13 \mathrm{KO} 7$ helper phage as negative control on the cell growth of MDA-MB-468 was observed ( $p>0.05$ ).

Conclusions: The selected anti-EGFR scFv with high anti proliferative effect on TNBC cells offers an effective alternative for TNBC targeted therapy. The antibody, which binds to the dimerization arm of EGFR and inhibits EGFR dimerization, could also overcome TNBC cases with Cetuximab resistance due to ligandindependent activating mutations.
\end{abstract}

Keywords: EGFR, Single chain antibody, TNBC, Targeted therapy.

\section{Introduction}

Triple-negative breast cancer (TNBC) is heterogeneous in molecular and clinical characteristics and accounts for about $15 \%-20 \%$ of breast cancer patients (1-3). TNBCs are often associated with poor outcomes, high distant metastases frequency including metastasis to brain, liver, and lung and, typically show a low overall survival compare to other breast cancer subtypes $(4,5)$. Chemotherapy is the only approved therapy for TNBC patients after surgery. Although TNBC patients have a better response to chemotherapy than non-TNBC cases,
TNBC prognosis remains poor with early relapses and metastasis (6-8).

The application of targeted therapy provides effective management of breast cancer in the past decade $(9,10)$. There are several approved-drugs especially monoclonal antibodies that target different molecular pathways and have promising results but due to lack of hormone receptors and epidermal growth factor receptor 2 (HER2), TNBC patients are not responsive to targeted therapies such as anti-HER2 and hormonal therapy and therefore, currently, there is no 
effective approved-targeted therapy to treat TNBC (11).

Epidermal growth factor receptor (EGFR) overexpression correlated with worse prognosis of various tumors including, lung, head and neck, gastrointestinal tract, colorectal, bladder, and breast cancers (12). In the lack of bound ligand, EGFR is a monomer and its dimerization arm is cryptic, however when the ligand binds to the ligand-binding site, it leads to a conformational change, and dimerization arm is exposed, which activates several signaling pathways $(13,14)$. RAF/MAPK and PI3K/AKT pathways are main signaling pathways that are activated by EGFR activation and contribute to various tumor supportive processes including proliferation, differentiation, migration, and inhibition of apoptosis (15). Monoclonal antibodies and tyrosine kinase inhibitors with a low molecular weight that target EGFR are present for the treatment of different cancer types such as colorectal cancer and non-small cell lung cancer, respectively $(16,17)$. Cetuximab and Panitumumab are two FDA-approved monoclonal antibodies for the treatment of colorectal cancer. These antibodies bind to the ligand binding site of EGFR, prevent ligandbinding, inhibit dimerization and activate downstream signaling pathways (18).

Therapeutic and diagnostic applications of recombinant antibodies are increasingly in medicine. Single-chain fragment variable ( $\mathrm{scFv}$ ) antibody is one of the small types of recombinant antibodies that contain antigen binding site of antibody (VH and VL) connected with a short and flexible linker. The small scFvs have better penetration ability into tissue. The other benefits of scFvs include human nature, low immunogenicity, high affinity and high specificity and ability to genetic manipulation, which have made these antibody fragments suitable candidate for cancer immunotherapy (19-23).

In this study, specific $\mathrm{scF} v$ against dimerization arm of EGFR was selected and the antitumor effect of the selected $\mathrm{scFv}$ on triple negative breast cancer cells was evaluated using MTT assay.

\section{Materials and methods \\ Phage Rescue}

A scFv library was produced as described previously (24). Escherichia coli (E. coli) containing phagemid was cultured on 2TYG agar containing ampicillin at $30{ }^{\circ} \mathrm{C}$ overnight. The bacteria colonies were scraped and incubated in 2TYG broth for one hr at $37^{\circ} \mathrm{C}$. M13KO7 helper phage was added and the bacteria were incubated at $37^{\circ} \mathrm{C}$ for $30 \mathrm{~min}$. Following centrifugation, the bacterial pellet was resuspended in $2 \mathrm{TY}$ broth containing ampicillin and kanamycin and incubated with shaking at $30{ }^{\circ} \mathrm{C}$ overnight. The culture was centrifuged, the supernatant that contained phage-scFvs harvested, filtered, and stored at $4{ }^{\circ} \mathrm{C}$.

\section{Panning procedure}

A polystyrene immunotube (Nunc, Denmark) was coated with the peptide (LYNPTTYQMD, amino acids $245-254$ of EGFR at $4{ }^{\circ} \mathrm{C}$ overnight. After washing with PBS, $2 \%$ skimmed milk was added to the tube and incubated at $37{ }^{\circ} \mathrm{C}$ for two hrs. The tube was washed four times with $1 \%$ (v/v) solution of Tween-20 in phosphate buffered saline (PBST) PBS and four times with phosphate buffered saline (PBS). The phage supernatant was diluted with an equal volume of $2 \%$ skimmed milk and incubated for one $\mathrm{hr}$ at room temperature with occasional inversions. After washing, bound phage scFvs were eluted by adding log-phase TG1 E. coli bacteria and incubation at $37{ }^{\circ} \mathrm{C}$ for one hr. The tube was centrifuged and the bacterial pellet was resuspended in $2 \mathrm{TY}$ broth media, plated on $2 \mathrm{TY}$ agar/ampicillin plates, and incubated at $30{ }^{\circ} \mathrm{C}$ overnight. Four rounds of panning were performed to select specific $\mathrm{scFv}$ antibodies against EGFR peptide.

\section{PCR and DNA Fingerprinting of the Selected Clones}

PCR was performed on 20 randomly selected clones obtained from the 4th round of panning to check VH-linker-VL insert. Each PCR product was digested by Mva-I restriction enzyme (Roche, Mannheim, Germany) at $37^{\circ} \mathrm{C}$ for $2 \mathrm{hrs}$ in a dry block heater to determine common patterns as specific scFv antibodies. 


\section{MTT assay}

Triple negative breast cancer cell line (MDAMB-468) at a density of $10^{4}$ cells/well was seeded in 96-well flat-bottomed plate (Nunc, Denmark) and incubated overnight at $37{ }^{\circ} \mathrm{C}$. Different concentrations of phage displayed antiEGFR $\mathrm{scFv}$ were added to the cells and incubated for 24 hours at $37^{\circ} \mathrm{C}$. M13KO7 helper phage was also used as a negative control. MTT [3-(4, 5-dimethylthiazol-2,

$5-$ diphenyltetrazolium bromide, $0.5 \mathrm{mg} / \mathrm{ml}$; Sigma, Germany] was added to each well followed by $4 \mathrm{~h}$ incubation at $37^{\circ} \mathrm{C}$. The supernatant was aspirated and the formazan crystals were dissolved by adding $100 \mu \mathrm{l}$ DMSO (Merck, Germany) and 15 min shacking. The absorbance was measured by Enzyme-Linked Immunosorbent Assay (ELISA) reader at a wavelength of $570 \mathrm{~nm}$. All experiments were performed in triplicates and the percentage of cell growth in each treated well was calculated using following formula:

Percentage of cell growth $=\left(\mathrm{OD}_{570}\right.$ treated $/$ $\mathrm{OD}_{570}$ untreated) $\times 100$.

\section{Statistical Analyses}

Data were analyzed by ANOVA test using GraphPad Prism software version 6 to compare the means of percentages of cell growth among different treatments. All data are presented as the mean \pm standard deviation. $p$ value $<0.05$ was considered statistically significant.

\section{Results}

PCR and DNA Fingerprinting of Anti-EGFR scFv Antibodies

After four rounds of panning against a specific peptide of EGFR, selected single colonies were evaluated by colony PCR to check the presence of $950 \mathrm{bp} \mathrm{scFv}$ gene inserts in the selected colonies. The interested band (950 bp) was observed (Fig. 1). DNA fingerprinting of the selected clones was performed to check the common pattern. As shown in Figure 2, one pattern was obtained with a frequency of $85 \%$ (lanes 1-8, 10-17 and 20). Lanes 9, 18 and 19 showed another pattern with frequency $15 \%$. The dominant pattern was selected for further investigations.

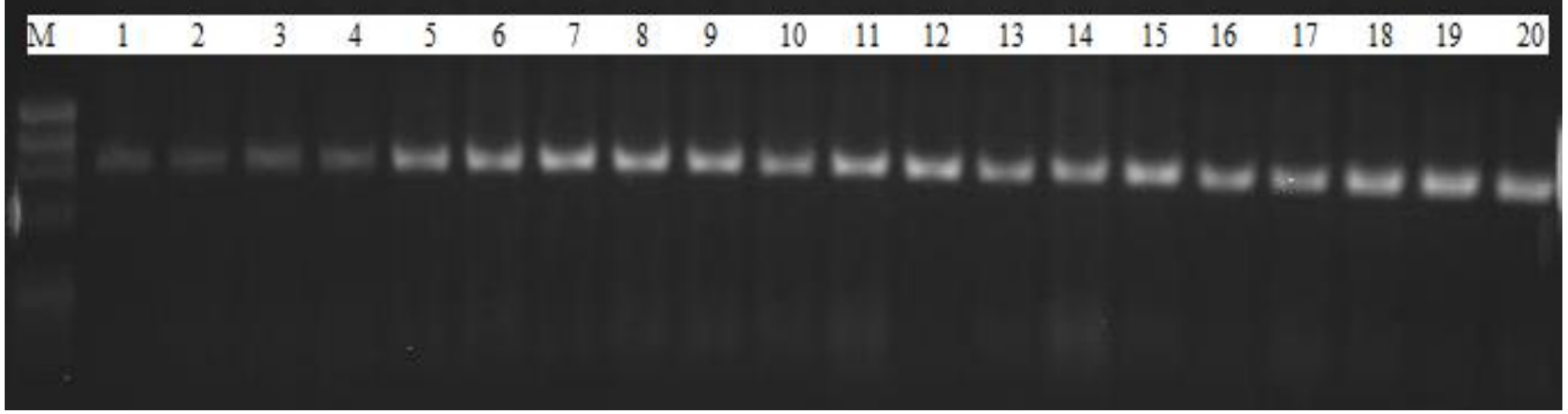

Fig. 1. PCR result of the isolated clones against EGFR after panning. M, marker- ØX174. A 950 bp band is seen in 1- 20 lanes.

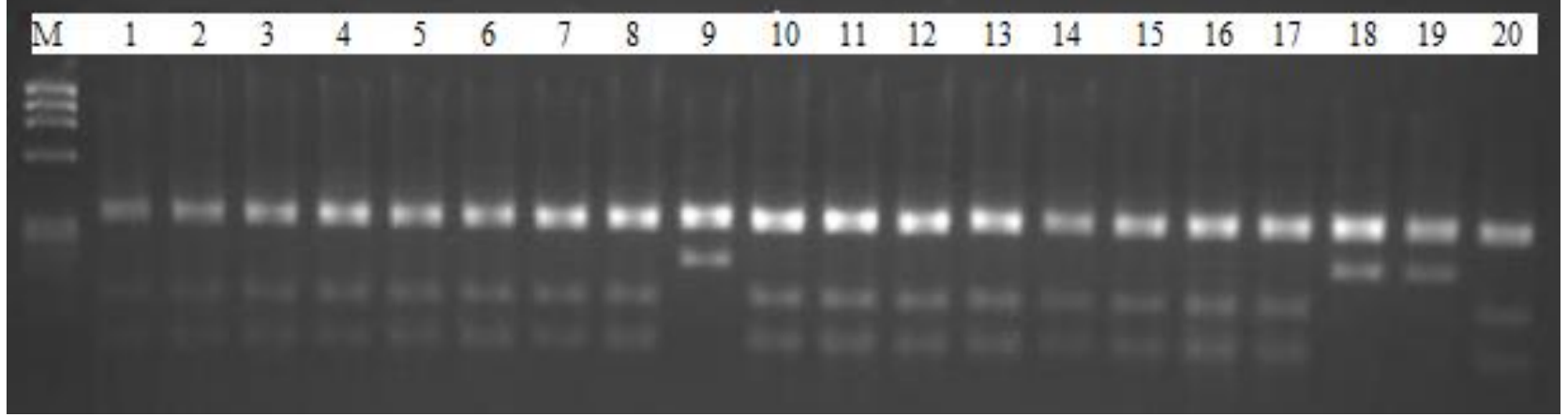

Fig. 2. DNA fingerprint patterns of randomly selected clones after four rounds of panning against EGFR. The frequency of dominant patterns is $85 \%$. M, marker- $\varnothing \mathrm{X} 174$. Two different pattern were detected. 
Anti-proliferative effects of phage displayed antiEGFR scFvs on a triple negative breast cancer cell line (MDA-MB-468)

The anti-proliferative effects of different concentrations (1000, 2000, 4000, and 8000 phages/cell) of anti-EGFR scFv on MDA-MB468 as an overexpressing EGFR were assessed by MTT assay. The growth of MDA-MB-468 cells was decreased dose-dependently after $24 \mathrm{hrs}$ treatment with anti-EGFR scFv (Fig. 3).

The percentages of growth inhibition of MDAMB-468 cells after 24 hrs of treatment with antiEGFR scFv (8000 phage/cell) was $50.01 \%$ while no significant inhibitory effect of $\mathrm{M} 13 \mathrm{KO} 7$ on the growth of MDA-MB-468 cells was observed ( $\mathrm{p}$ > 0.05) (Fig. 4).

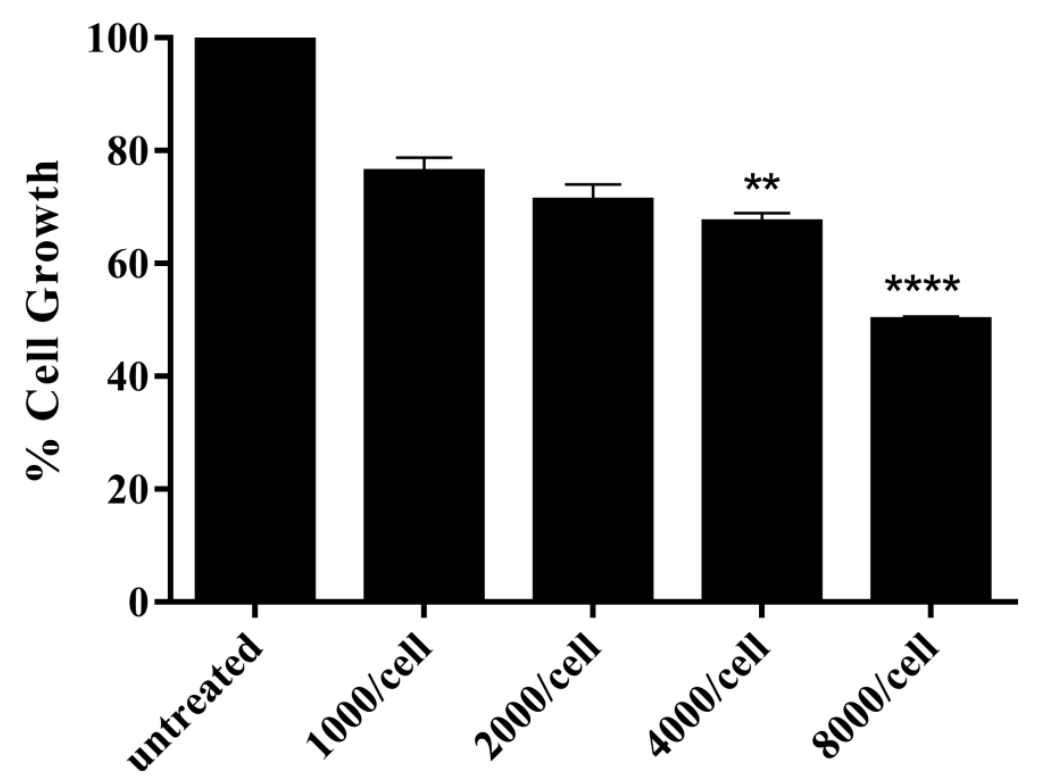

Fig. 3. Percentage of the cell growth in MDA-MB-468 after 24 hrs treatment with different concentrations of phage displayed antiEGFR scFv. The maximum effect of anti-EGFR scFv (50.01\%) was obtained in cells treated with 8000 phages/cell of the scFv, p< 0.05 .

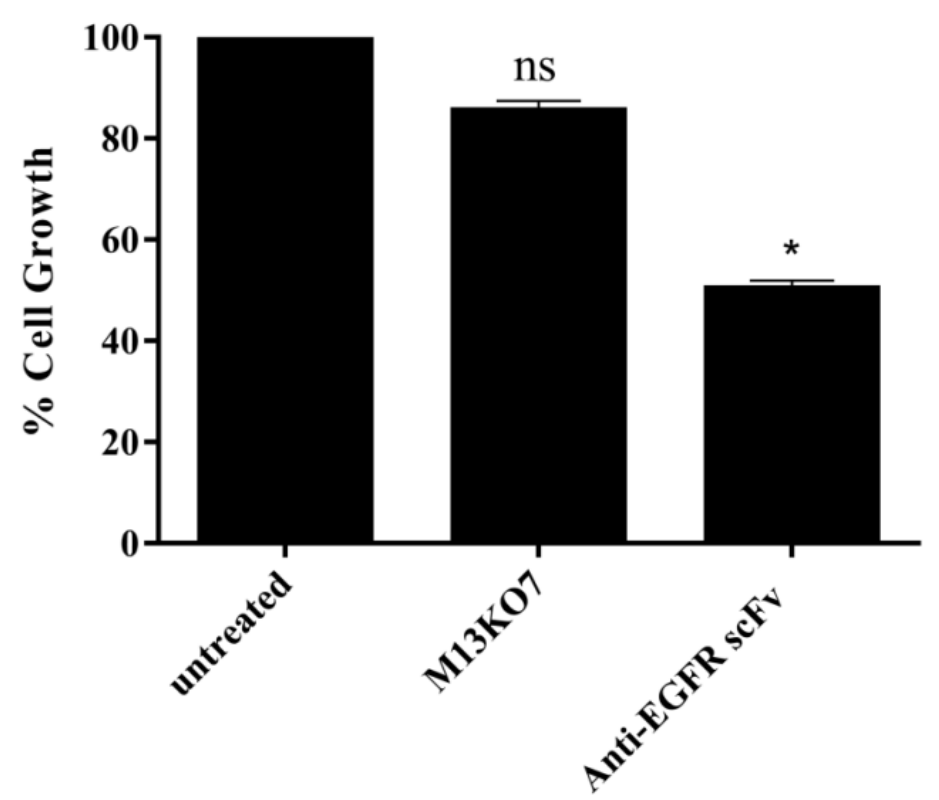

Fig. 4. Percentage of cell growth in MDA-MB-468 after $24 \mathrm{~h}$ treatment with phage displayed anti-EGFR scFv and M132KO7. No growth inhibition was obtained in cells treated with M13KO7 while cells treated with anti-EGFR scFv showed $50.01 \%$ growth inhibition, $\mathrm{p}<0.05$. 


\section{Discussion}

Targeted therapy is a new anti-tumor approach, which is considered to have an important role in the inhibition of tumor growth (25). Due to several advantages of human single chain antibodies, these effective agents have been applied for cancer targeted therapy and promising results have been achieved $(26,27)$.

In this study, a library of human scFv was used to select specific anti-EGFR scFv. The epitope that was used for the selection of specific $\mathrm{scFv}$ was obtained from the dimerization arm of EGFR (LYNPTTYQMD, amino acids 245-254 of EGFR) (28). Polyclonal antisera of rabbit that was injected with this polypeptide could bind to the polypeptide and decreased the tyrosine phosphorylation of EGFR (29). Mizuguchi et al used a synthetic peptide that could mimic the loop of the dimerization arm and revealed that the peptide inhibited the dimerization and autophosphorylation of EGFR in epidermoid carcinoma A431 cells (30). Also in another study, a proteolytically stable and biologically active form of the peptide was designed and has been shown that the peptide can downregulates receptor phosphorylation and dimerization of EGFR and reduces cell growth (31).

In the current study, following four rounds of panning against the EGFR epitope, DNA fingerprinting results showed a common pattern with $85 \%$ frequency. The panning process has been widely applied to select specific scFvs against different targets. Mohammadi et al. selected specific $\mathrm{scFv}$ against MUC18 using panning procedure (32). Specific antibodies against CD90, a cancer stem cell marker, were selected by panning using the phage display technology (33). Selection of specific scFv antibodies against Frizzled receptor 7 (FZD7) by panning procedure have shown high inhibitory effects of the scFvs on breast cancer cell growth (34).

Results of the anti-proliferation effect of antiEGFR scFv antibody on TNBC cell demonstrated that cell growth of MDA-MB-468 cells was inhibited dose-dependently after $24 \mathrm{~h}$ treatment. The maximum effect of anti-EGFR $\mathrm{scFv}$ $(50.01 \%)$ was obtained in cells treated with 8000 phages/cell of the $\mathrm{scFv}$, while no significant inhibitory effect for $\mathrm{M} 13 \mathrm{KO} 7$ as a negative control on the cell growth of MDA-MB-468 cells was observed, which indicates that the inhibitory effects are due to the specific single-chain antibodies. Compared to other breast cancer subtypes, EGFR is more commonly overexpressed in TNBC tumors, and EGFR overexpression has been identified as a poor prognosis factor for TNBC (8). Blocking of EGFR dimerization arm by the selected antiEGFR $\mathrm{scFv}$ which leads to a high antiproliferative effect offers the use of the selected scFv in TNBC tumors with high EGFR expression. Blocking of EGFR by two approved anti-EGFR monoclonal antibodies, Cetuximab and Panitumumab, resulted in a 20 to $30 \%$ growth inhibition of MDA-MB-468 cells compared to untreated cells. Also, Gefitinib as tyrosine kinase inhibitor of EGFR, reduced viability of TNBC cell line about $38 \%$, and when Gefitinib combined with Cetuximab, the TNBC cell viability reduction increased up to $60 \%$ (35).

Various advantages of fully-human $\mathrm{scFv}$ antibody fragments over monoclonal antibodies have attracted attention for tumor-targeted therapy by scFv. Specific scFvs against alpha-fetoprotein (AFP) and Integrin $\alpha v \beta 3$ have been shown as effective anti-tumor agents in vitro and in vivo $(36,37)$. Also, scFvs were conjugated with different substances including toxin, cytokine, nanoparticle, and fluorochrome and were applied in therapeutic and diagnostic applications (38-41). Several EGFR-targeted antibody-drugs conjugates have shown great potential for TNBC treatment and are currently undergoing clinical trials for TNBC patients (42). Selected scFv in the current study has the potential to be used for EGFR inhibition and TNBC treatment. Results of anti-proliferative effects demonstrated growth inhibition of MDA-MB-468 cells, as the antibody binds to the dimerization arm of EGFR and inhibits the signaling pathway, inhibition of cell proliferation occurs. EGFR overexpression is observed in at least 50 percent of TNBC patients (43) and high EGFR expression correlated with enhanced tumorigenesis and metastasis in TNBC 
(44) therefore, targeting EGFR by specific $\mathrm{scFV}$ antibody with high anti-proliferative effect can be an ideal treatment strategy.

Cetuximab binds to the ligand-binding site of EGFR and blocks this site, resulting in the inhibition of subsequent cell growth signaling (45) while ligand-independent activating mutations occur in the gene of EGFR in some tumors including TNBC that leads to Cetuximab resistance $(8,46-48)$. Specific anti-EGFR scFv, which inhibits EGFR dimerization and leads to a

\section{References}

1. Wang Y, Zhang G, Han J. HIF1A-AS2 predicts poor prognosis and regulates cell migration and invasion in triple-negative breast cancer. Journal of cellular biochemistry. 2019;120(6):10513-8.

2. Vikas P, Borcherding N, Zhang W. The clinical promise of immunotherapy in triplenegative breast cancer. Cancer Manag Res. 2018; 10:6823-6833.

3. Levva S, Kotoula V, Kostopoulos I, Manousou K, Papadimitriou C, Papadopoulou $\mathrm{K}$, et al. Prognostic evaluation of epidermal growth factor receptor (EGFR) genotype and phenotype parameters in triple-negative breast cancers. Cancer Genomics Proteomics. 2017;14(3):181-195.

4. Siddharth S, Sharma D. Racial disparity and triple-negative breast cancer in AfricanAmerican women: a multifaceted affair between obesity, biology, and socioeconomic determinants. Cancers. 2018;10(12):514.

5. Baselga J, Gómez P, Greil R, Braga S, Climent MA, Wardley AM, et al. Randomized phase II study of the anti-epidermal growth factor receptor monoclonal antibody cetuximab with cisplatin versus cisplatin alone in patients with metastatic triple-negative breast cancer. J Clin Oncol. 2013;31(20):2586-92.

6. Ueno NT, Zhang D. Targeting EGFR in triple negative breast cancer. $\mathrm{J}$ Cancer. 2011;2:324-8.

7. Reguera-Nuñez E, Xu P, Chow A, Man S, Hilberg F, Kerbel RS. Therapeutic impact of Nintedanib with paclitaxel and/or a PD-L1 antibody in preclinical models of orthotopic high antiproliferative effect, may overcome Cetuximab resistance in TNBC and other cancers due to ligand-independent activating mutations in the gene of EGFR.

\section{Acknowledgment}

The authors acknowledge Shiraz University of Medical Sciences for financial support. This article is extracted from the thesis written by Forough Abdollahzadeh with grant no. 18033.

primary or metastatic triple negative breast cancer. J Exp Clin Cancer Res. 2019;38(1):16.

8. Nakai K, Hung M-C, Yamaguchi H. A perspective on anti-EGFR therapies targeting triple-negative breast cancer. American journal of cancer research. 2016;6(8):1609-1623.

9. Gatzka M. Targeted tumor therapy remixedAn update on the use of small-molecule drugs in combination therapies. Cancers (Basel). 2018;10(6): 155 .

10. Hortobagyi GN. Trastuzumab in the treatment of breast cancer. The New England journal of medicine. 2005;20;353(16):1734-6.

11. Walsh EM, Keane MM, Wink DA, Callagy G, Glynn SA. Review of triple negative breast Cancer and the impact of inducible nitric oxide synthase on tumor biology and patient outcomes. Crit Rev Oncog. 2016;21(5-6):333351.

12. Spano J, Fagard R, Soria J-C, Rixe O, Khayat D, Milano G. Epidermal growth factor receptor signaling in colorectal cancer: preclinical data and therapeutic perspectives. Annals of oncology. 2005;16(2):189-194.

13. Lemmon MA, Schlessinger J, Ferguson KM. The EGFR family: not so prototypical receptor tyrosine kinases. Cold Spring Harb perspect biol. 2014;6(4):a020768.

14. Sigismund S, Avanzato D, Lanzetti L. Emerging functions of the EGFR in cancer. Mol oncol. 2018;12(1):3-20.

15. Krasinskas AM. EGFR signaling in colorectal carcinoma. Patholog Res Int. 2011;2011:932932.

16. Omarini C, Guaitoli G, Pipitone S, 
Moscetti L, Cortesi L, Cascinu S, et al. Neoadjuvant treatments in triple-negative breast cancer patients: where we are now and where we are going. Cancer Manag Res. 2018;10:91-103.

17. Flynn JF, Wong C, Wu JM. Anti-EGFR therapy: mechanism and advances in clinical efficacy in breast cancer. Journal of oncology. 2009;2009:526963.

18. Seshacharyulu P, Ponnusamy MP, Haridas D, Jain M, Ganti AK, Batra SK. Targeting the EGFR signaling pathway in cancer therapy. Expert Opin Ther Targets. 2012;16(1):15-31.

19.Nejatollahi F, Silakhori S, Moazen B. Isolation and evaluation of specific human recombinant antibodies from a phage display library against her3 cancer signaling antigen. Middle East Journal of Cancer. 2014;5(3):137-144.

20. Moazen B, Ebrahimi E, Nejatollahi F. Single Chain Antibodies Against gp55 of Human Cytomegalovirus (HCMV) for Prophylaxis and Treatment of HCMV Infections. Jundishapur J Microbiol. 2016;9(3):e16241.

21. Mohammadi M, Nejatollahi F, Sakhteman A, Zarei N. Insilico analysis of three different tag polypeptides with dual roles in $\mathrm{scFv}$ antibodies. Journal of theoretical biology. 2016;402:100-106.

22. Nejatollahi F, Bayat P, Moazen B. Cell growth inhibition and apoptotic effects of a specific anti-RTFscFv antibody on prostate cancer, but not glioblastoma, cells. F1000Research. 2017;6:156.

23. Hosseinzadeh F, Mohammadi S, Nejatollahi F. Production and evaluation of specific single-chain antibodies against CTLA4 for cancer-targeted therapy. Rep Biochem Mol Biol. 2017;6(1):8-14.

24. Nejatollahi F, Hodgetts SJ, Vallely PJ, Burnie JP. Neutralising human recombinant antibodies to human cytomegalovirus glycoproteins $\mathrm{gB}$ and $\mathrm{gH}$. FEMS Immunol Med Microbiol. 2002;34(3):237-44.

25. Lheureux S, Denoyelle C, Ohashi P, De Bono J, Mottaghy F. Molecularly targeted therapies in cancer: a guide for the nuclear medicine physician. Eur J Nucl Med Mol Imaging. 2017;44(Suppl 1):41-54.
26. Safdari Y, Ahmadzadeh V, Khalili M, Jaliani HZ, Zarei V, Erfani-Moghadam V. Use of single-chain antibody derivatives for targeted drug delivery. Mol Med. 2016;22:258-270.

27. Ahmad ZA, Yeap SK, Ali AM, Ho WY, Alitheen NBM, Hamid M. scFv antibody: principles and clinical application. Clin Dev Immunol. 2012;2012:980250.

28. Mohammadi SS, Hosseinzadeh F, Nejatollahi F. Production of Specific AntiEGFR Single Chain Antibodies: A Promising Strategy in the Immunotherapy of EGFR Expressing Tumor Tissues. Iranian Journal of Cancer Prevention. 2017;10(1):1-6.

29. Chao G, Olsen M, Wolf-Yadlin A, Wittrup $\mathrm{K}$, Lauffenburger D. Epidermal growth factor receptor polypeptides and antibodies. Google Patents; 2007.

30. Mizuguchi T, Ohara N, Iida M, Ninomiya $\mathrm{R}$, Wada S, Kiso Y, et al. Evaluation of dimerization-inhibitory activities of cyclic peptides containing a $\beta$-hairpin loop sequence of the EGF receptor. Bioorganic \& medicinal chemistry. 2012;20(19):5730-5737.

31. Hanold LE, Oruganty K, Ton NT, Beedle AM, Kannan N, Kennedy EJ. Inhibiting EGFR dimerization using triazolyl-bridged dimerization arm mimics. PloS one. 2015;10(3):e0118796.

32. Mohammadi M, Nejatollahi F, Ghasemi Y, Faraji SN. Anti-metastatic and anti-invasion effects of a specific anti-MUC18 scFv antibody on breast cancer cells. Appl Biochem Biotechnol. 2017;181(1):379-390.

33. Moazen B, Zarrinhaghighi A, Nejatollahi F. Selection and Evaluation of Specific Single Chain Antibodies against CD90, a Marker for Mesenchymal and Cancer Stem Cells. Rep Biochem Mol Biol. 2018;7(1):45-51.

34. Zarei N, Fazeli M, Mohammadi M, Nejatollahi F. Cell growth inhibition and apoptosis in breast cancer cells induced by antiFZD7 scfvs: Involvement of bioinformaticsbased design of novel epitopes. Breast cancer research and treatment. 2018;169(3):427-436.

35. El Guerrab A, Bamdad M, Kwiatkowski F, Bignon Y-J, Penault-Llorca F, Aubel C. AntiEGFR monoclonal antibodies and EGFR tyrosine kinase inhibitors as combination 
therapy for triple-negative breast cancer. Oncotarget. 2016;7(45):73618-73637.

36. Ji X, Shen Y, Sun H, Gao X. A novel antialpha-fetoprotein single-chain variable fragment displays anti-tumor effects in HepG2 cells as a single agent or in combination with paclitaxel. Tumor Biology. 2016;37(8):10085-96.

37. Liu D, Wang C, Li C, Zhang X, Zhang B, Mi Z, et al. Production and Characterization of a humanized single-chain antibody against human integrin $\alpha v \beta 3$ protein. J Biol Chem. 2011;286(27):24500-24507.

38.Tur MK, Huhn M, Thepen T, Stocker M, Krohn R, Vogel S, et al. Recombinant CD64specific single chain immunotoxin exhibits specific cytotoxicity against acute myeloid leukemia cells. Cancer Res. 2003;63(23):8414-9. 39. Schanzer JM, Fichtner I, Baeuerle PA, Kufer P. Antitumor activity of a dual cytokine/single-chain antibody fusion protein for simultaneous delivery of GM-CSF and IL-2 to Ep-CAM expressing tumor cells. J Immunother. 2006;29(5):477-88.

40. Alric C, Herve-Aubert K, Aubrey N, Melouk S, Lajoie L, Même W, et al. Targeting HER2-breast tumors with scFv-decorated bimodal nanoprobes. J Nanobiotechnology. 2018;16(1):18.

41. Morino K, Katsumi H, Akahori Y, Iba Y, Shinohara M, Ukai Y, et al. Antibody fusions with fluorescent proteins: a versatile reagent for profiling protein expression. $\mathrm{J}$ Immunol Methods. 2001;257(1-2):175-84.

42. Costa R, Shah AN, Santa-Maria CA, Cruz
MR, Mahalingam D, Carneiro BA, et al. Targeting Epidermal Growth Factor Receptor in triple negative breast cancer: New discoveries and practical insights for drug development. Cancer Treat Rev. 2017;53:111-119.

43. Masuda H, Zhang D, Bartholomeusz C, Doihara H, Hortobagyi GN, Ueno NT. Role of epidermal growth factor receptor in breast cancer. Breast Cancer Res Treat. 2012;136(2):331-45.

44. Savage P, Blanchet-Cohen A, Revil T, Badescu D, Saleh SMI, Wang YC, et al. A Targetable EGFR-Dependent Tumor-Initiating Program in Breast Cancer. Cell reports. 2017;21(5):1140-1149.

45. Hubbard SR. EGF receptor inhibition: attacks on multiple fronts. Cancer cell. 2005;7(4):287-8.

46. Ruan Z, Kannan N. Altered conformational landscape and dimerization dependency underpins the activation of EGFR by $\alpha \mathrm{C}-\beta 4$ loop insertion mutations. Proc Natl Acad Sci U S A. 2018;115(35):E8162-E8171.

47. Valley CC, Arndt-Jovin DJ, Karedla N, Steinkamp MP, Chizhik AI, Hlavacek WS, et al. Enhanced dimerization drives ligandindependent activity of mutant EGFR in lung cancer. Mol Biol Cell. 2015;26(22):4087-4099. 48. Budhiarko D, Putra T, Harsono A, Masykura N, Tjindarbumi D, Widjajahakim G, et al. Frequency of L858R and L861Q EGFR mutation in triple-negative, luminal and HER2 of Indonesian breast cancers patients. Annals of Oncology. 2017;28(Suppl_10):X171. 